\title{
“É UM MUNDO NOVO NÉ, A GENTE NÃO TEM ESSA PREPARAÇÃO, ESSA FORMAÇÃO NA UNIVERSIDADE": (re)configurações do agir de uma professora de língua inglesa a alunos com necessidades específicas visuais ${ }^{42}$
}

\section{“IT IS A NEW WORLD AND OUR UNIVERSITY DOESN'T PREPARE US FOR THIS": (re)configuration of an english teacher's practice to students with visual impairment}

\author{
Náthaly Guisel Bejarano Aragón ${ }^{43}$
}

\begin{abstract}
RESUMO: Este artigo tem como objetivo investigar como os elementos constitutivos do trabalho docente de uma professora de língua inglesa a alunos com necessidades específicas visuais indiciam (re)configurações do seu agir linguageiro, a partir das vozes da professora colaboradora desta pesquisa, atuante no Instituto dos Cegos da Paraíba (doravante ICP). Os pressupostos teóricos utilizados se pautam no quadro teórico-metodológico do Interacionismo Sociodiscursivo (doravante ISD) proposto por Bronckart $(2006,2008)$ e das Ciências do Trabalho - Clínica da Atividade e Ergonomia - com base em Clot (2007) e Amigues (2004), especificamente no que se refere aos objetos constitutivos do agir docente e ao conceito de trabalho. Alicerçados nessas abordagens teóricas, para a geração de dados fizemos uso do instrumento Instrução ao Sósia (CLOT,2007) da Clínica da Atividade. Ao analisarmos as vozes da colaboradora as ferramentas foi o elemento que mais incidiu no discurso da colaboradora; as regras do ofício foi o segundo elemento que se fez presente, dando seguimento as prescrições e os coletivos. Finalmente, percebemos que na apropriação de novas ferramentas e na adoção de novas regras de ofício, nossa docente do ICP sente a necessidade de (re)configurar seu agir com o objetivo de propiciar uma participação ativa no processo de ensino-aprendizagem de língua inglesa.
\end{abstract}

PALAVRAS-CHAVE: Linguística Aplicada. ISD. Agir docente. Educação Inclusiva. Deficiência visual.

ABSTRACT: This article aims at investigating how the elements, that constitute the educational work of an English teacher to students with visual impairment, indicate reconfigurations of her language practice. For this discussion, we analyzed the teacher's speech from her experiences at a non-governmental organization to support blind people called Instituto dos Cegos da Paraíba - ICP. The theoretical framework is based on the Sociodiscursive Interactionism - ISD (BRONCKART, 2006, 2008) and on the Labor Sciences - Ergonomics and Activity Clinic (CLOT, 2007; AMIGUES, 2004), specifically the elements that constitute the teaching activity and the concept of work. Therefore, the data was generated through the procedure from Activity Clinic named 'Instruction to the Double' (CLOT, 2007). The analysis has demonstrated that the most recurring elements in the teacher's speech were: first, the tools; second, the rules of the work; third, the prescriptions; and fourth, the collectives. Finally, we realized that during the appropriation of new tools and the adoption of new rules of the work, our collaborator felt the need to (re)configure her practice, in order to provide an active participation in the teaching-learning process of English language.

KEYWORDS: Applied Linguistics. Sociodiscursive Interactionism. Teaching Practice. Inclusive Education. Visual Impairment.

\section{Introdução}

Partindo do pressuposto de que incluir é diferente de integrar e que a inclusão não deve ser compreendida como uma fase mais avançada da integração ${ }^{44}$ (COSTA, 2012). O

\footnotetext{
42 Recorte da dissertação de mestrado intitulada "(Re)configurações do agir docente: o ensino de língua estrangeira a alunos com necessidades específicas visuais à luz do ISD e das Ciências do Trabalho" e defendida em 2016 (PROLING/UFPB) sob a orientação da Profa. Dra. Carla Lynn Reichmann.

${ }^{43}$ Mestre em Linguística pela Universidade Federal da Paraíba - UFPB -, professora efetiva do Departamento de Letras e coordenadora da Especialização em Letras: Estudos Linguísticos e Literários da Universidade Estadual da Paraíba - UEPB-, Campus VI. E-mail: nathalyba21@hotmail.com

44 [...] a integração deixou intocáveis os valores menos inclusivos da escola. Não foi por causa da integração que o insucesso e o abandono escolar diminuíram; a integração criou frequentemente uma escola especial paralela à
} 
paradigma da inclusão vem para questionar políticas, a organização educacional especial e regular, assim como o próprio conceito de integração (MANTOAN, 2015). Assim, destacamos a importância da Educação Inclusiva, já que esta se "constitui um paradigma educacional fundamentado na concepção de direitos humanos, que conjuga igualdade e diferença como valores indissociáveis" (BRASIL, 2007, p. 1).

Nessa perspectiva, onde a igualdade e a diferença estão presentes, a (re)configuração do agir do professor em sala de aula com alunos com necessidades específicas visuais (NEV) se torna essencial para viabilizar esta inclusão. O docente inclusivo não procura eliminar a diferença em favor de uma suposta igualdade do alunado [...] Ele está atento aos diferentes tons de vozes que compõem uma turma, promovendo harmonia, dialogo, contrapondo-as, complementando-as (MANTOAN, 2015, p. 79).

Isto é, a (re)configuração deve levar a uma reflexão no e sobre o agir docente e consequentemente a uma ressignificação do papel do professor em sala de aula, na educação como um todo e na sociedade.

Diante deste contexto, este estudo encontra-se inserido dentro da Linguística Aplicada (LA) por entendermos a pesquisa como um modo de construir/renarrar a vida social, pois a vemos como um caminho para criar inteligibilidade sobre a vida contemporânea, e ao mesmo tempo, uma forma de colaborar com estudos sociais que tenham como base as vozes dos que se encontram à margem (MOITA LOPES, 2006). A essas vozes sociais, Boaventura Santos (2001) chama de "vozes do sul", isto é, sujeitos sócio-históricos de nossa realidade social. Com essa concepção de LA optamos por um estudo de cunho qualitativo-interpretativista, haja vista que este está aberto à complexidade do real e à interdisciplinaridade (SIGNORINI, 1998).

Nessa explanação, neste artigo objetivamos investigar como os elementos constitutivos do trabalho docente de uma professora de lingua inglesa a alunos com necessidades específicas visuais indiciam (re)configurações do seu agir linguageiro. Buscando alcançar o objetivo a que nos propusemos e com o intuito de compreender o trabalho dessa professora que atua no Instituto dos Cegos da Paraíba (ICP), fazemos algumas considerações sobre os pressupostos teórico metodológicos do Interacionismo Sociodiscursivo (ISD) e dos aportes teóricos das Ciências do Trabalho - Clínica da Atividade e Ergonomia, principalmente no que se refere aos objetos constitutivos do trabalho docente e seus conceitos sobre trabalho. Depois explicitamos a geração de dados que foi efetivada por meio do instrumento de Instrução ao Sósia. A seguir, apresentamos a leitura dos nossos dados, isto é, a leitura que fizemos da voz da professora entrevistada e, para finalizar, apresentamos nossas considerações finais.

\section{ISD e as Ciências do Trabalho: algumas considerações}

Segundo Bronckart (2006) o trabalho se constitui como uma atividade própria da espécie humana. Quando nos referimos ao trabalho docente, este teórico afirma que é difícil descrevê-lo, caracteriza-lo e, até mesmo, de simplesmente "falar dele". Machado (2007) com base em Clot (2007) e Amigues (2004) complementa essa concepção de trabalho e destaca que essa atividade é situada, pois sofre influência do contexto imediato ou amplo; é pessoal e sempre única, por engajar o trabalhador em suas dimensões físicas, cognitivas, emocionais, e ao mesmo tempo é impessoal, haja vista que não se desenvolve de forma totalmente livre,

escola regular em que os estudantes com a categoria de "deficientes" tinham condições especiais de frequência. Em segundo lugar, a escola integrativa separava os estudantes em dois tipos: os "normais" e os "deficientes" [...] Em terceiro lugar, o papel do aluno "deficiente" na escola integrativa foi sempre condicionado [...] o aluno só se poderia manter na escola enquanto o seu comportamento e aproveitamento fossem adequados [...] o aluno com dificuldades não era um membro de pleno direito da escola (RODRIGUES, 2006, p. 303-304). 
devido às tarefas prescritas por instâncias superiores e externas a ele; é prefigurada pelo próprio trabalhador, visto que, assim como ele reelabora as prescrições para si mesmo também as constrói.

Por outro lado, é mediada por instrumentos materiais ou simbólicos, já que se apropria de artefatos socialmente construídos e disponibilizados pelo meio social; é interpessoal, porque interage com vários outros indivíduos, presentes ou ausentes na sua situação de trabalho; é transpessoal, já que é orientada por modelos dos agires específicos a cada ofício, construídos sócio-historicamente pelos coletivos de trabalho. Por último, é também conflituosa, em vista de que o trabalhador se vê em situações tão específicas nas quais precisa (re)direcionar seu agir, quando se depara com vozes contraditórias, com o agir dos outros, com o meio, com os artefatos e as prescrições.

Como consequência desta última característica mencionada, a atividade de trabalho é fonte de aprendizagem e consequentemente propicia o desenvolvimento de capacidades do trabalhador. Pode ser também fonte de impedimento tanto para a aprendizagem quanto para seu desenvolvimento, haja vista que o trabalhador se vê diante de dilemas intransponíveis que lhe tiram o poder de agir, este acaba gerando estresse e até desistência de trabalhar no seu ofício (MACHADO, 2007). Esta situação vivida pelos docentes de língua estrangeira referese ao momento em que se deparam com alunos com NEV ou qualquer outra necessidade específica. A carência de uma formação inicial e continuada que dialoguem com o paradigma da inclusão torna o ensino a este público um dilema.

Nesta explanação, é importante que esclareçamos o que consideramos agir. Para o ISD é "qualquer forma de intervenção orientada de um ou de vários seres humanos no mundo" (BRONCKART, 2008, p. 120) isto é, orientada por motivos, razões e capacidades. Desta feita, qualquer trabalho que seja desenvolvido por algum indivíduo, deve ser considerado um tipo de agir. Assim, ensinar é agir, visto que este se desenvolve visando um objetivo e consequentemente exige que o professor interaja com o meio, com o coletivo, que se aproprie de ferramentas para a execução de uma determinada tarefa.

Continuando com esta discussão, as Ciências do Trabalho também contribuem para um melhor entendimento do trabalho docente. Ao considerar que esta atividade não depende só dele, mas que recebe influência de fatores externos além das prescrições que condicionam seu agir. Amigues (2004), Bueno (2007), Guimarães (2007), Machado (2007) entre outros, destacam e problematizam os elementos constitutivos do agir docente.

O primeiro deles são as prescrições, que segundo Amigues (2004), desempenham um papel decisivo do ponto de vista da atividade. Estas além de cumprir a função de desencadeadoras da ação do professor, também constituem sua atividade ao serem redefinidas por ele, já que elas são vagas. Por outro lado, são definidas também como as limitações/ coerções/regras/normas explicitamente tematizadas em textos, que são direcionadas aos trabalhadores e produzidas por uma instância hierarquicamente superior (BERTHET E CRU, 2002 apud BUENO, 2007). É interessante mencionar que podem ser internas ou externas ao local de trabalho, além de compreender objetivos a serem atingidos, procedimentos a serem realizados, assim como apresentar diversidade de regras.

O segundo objeto constitutivo do trabalho do professor são as regras do ofício, estas se constroem no decorrer da história e se referem àquilo que liga os profissionais entre si (BUENO, 2007), isto é, uma memória comum, uma caixa de ferramentas, onde as regras podem reunir gestos relativos, por exemplo, ao conjunto de professores, e gestos específicos, como os adotados em disciplinas (AMIGUES, 2004). São estas regras que propiciam uma renovação, reconfiguração dos modos de fazer, isto é, torna-se elemento essencial para a compreensão do gênero profissional. Exemplos dessas regras do ofício são a forma de organização de uma aula onde suas partes independem do professor ou da escola, já que são as mesmas para a maioria. 
No trabalho docente se lança mão de ferramentas que podem ser do tipo material (giz, quadro, etc.) ou simbólico (prescrições, regras de ofício, livros didáticos, etc.) e construídas sócio-historicamente. De acordo com Amigues (2004), é frequente que o professor utilize as concebidas por outros do que as elaboradas por ele mesmo, e são frequentemente transformadas quando consideradas úteis e necessárias para seu agir, isto é, podem ou não ser apropriadas pelo trabalhador (BUENO, 2007). Contudo, acreditamos que o professor também prefira as ferramentas que ele mesmo elabora, após usá-las e verificar que se tornaram úteis para alcançar o objetivo proposto. Assim, ao serem apropriadas, estas promovem o desenvolvimento da ação e a organização do seu próprio agir. A esta transformação dá-se o nome de gênese instrumental.

Por último, os coletivos estão presentes em diversos momentos do trabalho do professor. Segundo Bueno, podem ser "tanto um grupo de pessoas como também uma memória coletiva que cada professor carrega em si, retomando-a a cada momento de seu trabalho para validar um artefato, questionar uma regra, criticar um comportamento, etc.94" (BUENO, 2007, p. 50). Assim, podemos perceber como são importantes no agir docente essas dimensões coletivas para o desenvolvimento do trabalho educacional. Seguidamente, apresentamos como foi gerado o corpus e construída a pesquisa.

\section{Aspectos metodológicos e constituição do corpus}

Optamos por um estudo de cunho qualitativo-interpretativista, porque como mencionamos em seção anterior, este está aberto à complexidade do real e à interdisciplinaridade (SIGNORINI, 1998). Por outro lado, enquadrar-se em um estudo interpretativista, implica ir em busca de entender e interpretar fenômenos sociais inseridos em um determinado contexto.

Para isto, Moita Lopes (1994, p. 332) afirma que "a padronização do mundo social e a redução da realidade a uma causa é uma distorção da realidade criada pela investigação científica". Sendo a pesquisa qualitativa uma abordagem interpretativa, para o mundo, implica que seus pesquisadores observem seus objetos de estudo em seus cenários naturais, tentando entender, ou interpretar, os fenômenos dos significados que as pessoas a eles conferem (DENZIN E LINCOLN, 2006).

Ao lidarmos com uma geração de dados, se faz necessário estar em contato com os indivíduos participantes da pesquisa, em contextos diversos, já que a abordagem qualitativa e principalmente interpretativista se preocupa não só com a produção do conhecimento, com a compreensão de significados e com a qualidade dos dados, mas também tem como valores a confiança, a responsabilidade, a veracidade, qualidade, a honestidade e respeitabilidade (CELANI, 2005).

A professora participante, à época da geração dos dados, estava terminando a licenciatura em Letras-Inglês e vinha ensinando língua inglesa havia 10 anos. Em junho de 2014 participou do Programa de Licenciaturas - PROLICEN e foi assim que teve a oportunidade de lecionar no Instituto dos Cegos da Paraíba, nosso contexto de pesquisa. Nessa instituição, ela lecionava a quatro alunos com cegueira total, ao longo deste estudo nos referiremos a ela pelo nome Carla.

Os dados foram gerados seguindo-se o seguinte processo:

\begin{tabular}{|l|l|}
\hline Passo 1 & $\begin{array}{l}\text { Entrevista pré-tarefa: Nela foram tratados quatro temas gerais versando sobre a } \\
\text { formação do professor, o tempo de ensino, sobre o ensino de línguas estrangeiras } \\
\text { a alunos com NEV e sobre o processo de inclusão. }\end{array}$ \\
\hline Passo 2 & $\begin{array}{l}\text { Gravação em áudio do procedimento Instrução ao Sósia (aula). É realizada pela } \\
\text { instrutora/colaboradora na modalidade de entrevista, uma descrição da sua }\end{array}$ \\
\hline
\end{tabular}




\begin{tabular}{|c|c|}
\hline & $\begin{array}{l}\text { atividade profissional, com o intuito de que a sósia/pesquisadora saiba como agir } \\
\text { se tivesse que substitui-la. A docente descreve sua tarefa no maior número de } \\
\text { detalhes possíveis respondendo à pergunta: Suponha que eu seja seu sósia e que } \\
\text { amanhã eu deva substituir você em seu trabalho. Que instruções você deveria me } \\
\text { transmitir para que ninguém perceba a substituição? (CLOT, 2007, p. 144). } \\
\text { Cabe esclarecer que esta substituição é hipotética e necessária para que a } \\
\text { instrutora possa se deslocar da sua atividade (CLOT, 2007) e ao realizar a } \\
\text { descrição do seu agir, trazer detalhes do trabalho. }\end{array}$ \\
\hline Passo 3 & $\begin{array}{l}\text { Elaboração de um comentário feito por escrito, pela professora participante deste } \\
\text { estudo, sobre a aula gravada em áudio. É importante destacar que este último } \\
\text { passo faz parte do procedimento Instrução ao Sósia. }\end{array}$ \\
\hline
\end{tabular}

Quadro 1: Procedimentos para geração do corpus

Diante do "desconhecimento da importância da descrição do próprio agir como contribuição para a identificação das minúcias da situação de trabalho" (TOGNATO, 2009, p. 109), justificamos o uso do instrumento Instrução ao Sósia da Clínica da Atividade por ser um procedimento indireto para a geração de dados. Métodos indiretos permitem uma "representação da experiência" (SAUJAT, 2002, p. 92), uma "reconstrução de uma nova experiência do passado no presente" (SAUJAT, 2002, p. 92).

Uma vez gerados os dados e baseados no objetivo delimitado, o procedimento de análise do corpus compreendeu, em um primeiro momento, a leitura e seleção de trechos identificando os objetos constitutivos presentes na fala da colaboradora. Ressaltamos que os objetos constitutivos do agir docente nos serviram como categorias de análise. Em um segundo momento, foram discutidas e interpretadas as mudanças identificadas nas práticas da professora em função dos objetos selecionados. Descritos os procedimentos metodológicos, damos passo à seção onde apresentamos a interpretação da fala da nossa colaboradora.

\section{Elementos constitutivos do agir docente e a educação inclusiva}

Nesta seção, buscamos fazer a leitura do agir da professora colaboradora da pesquisa, Carla. A análise desenvolvida neste artigo foi realizada considerando como categorias de análise os objetos constitutivos do agir docente sugeridos por Amigues (2004), Machado (2007), Bueno (2007) e Guimarães (2007), quais sejam: as ferramentas, as prescrições, as regras do oficio e os coletivos.

\subsection{As ferramentas}

Partindo da premissa de que uma ferramenta se torna instrumento a partir do momento em que o docente a considera útil para a execução de sua tarefa (BUENO, 2007), iniciamos esta análise identificando as ferramentas, que podem ser de ordem material ou simbólica e podem ou não ser apropriadas pelo docente. Na voz da colabora Carla identificamos os rods ${ }^{45}$ e a tampa de caneta e borracha na categoria das ferramentas materiais e nas simbólicas a

\footnotetext{
${ }^{45}$ O Material foi criado pelo professor belga Georges Cuisenaire Hottelet (1891-1980) depois de ter observado o desespero de um aluno, numa das suas aulas. Decidiu criar um material que ajudasse no ensino dos conceitos básicos da Matemática. Então, cortou algumas réguas de madeira em 10 tamanhos diferentes e pintou cada peça de uma cor, tendo assim surgido a Escala de Cuisenaire. Feito originalmente de madeira, o Cuisenaire é constituído por modelos de prismas quadrangulares com alturas múltiplas da do cubo, em 10 cores diferentes e 10 alturas proporcionais. Cuisenaire Rods: http://www.cuisenaire.co.uk/.
} 
metodologia de leitura em Braille. No segmento (01) podemos conferir que os rods ainda estão em processo de apropriação pela professora Carla, vejamos:

(1) Carla

então daí:: na verdade estou dizendo isso mas eu nunca dei aula disso, vai ser a primeira vez que vou trabalhar os rods, eu SÓ vi as professoras dando aula com os rods, mas eu nunca usei, então

Nesse trecho, confirmamos o afirmado por Amigues (2004) na questão dos docentes utilizarem prioritariamente ferramentas concebidas por outros. Na fala da professora Carla, ela é bastante clara ao mencionar que seria a primeira vez que iria trabalhar com os rods e que até então só tinha visto as professoras usando-os. Por outro lado, esses outros mencionados por Amigues, neste caso, seriam a coordenadora de projeto PROLICEN, também voluntária no ensino de língua inglesa no ICP e uma ex-bolsista de projetos anteriores que atualmente também é voluntária e pesquisadora da área da educação inclusiva.

$\mathrm{Na}$ voz de Carla, notamos a importância das professoras que já se apropriaram dos rods e que serviram como pares superiores sobre como este material pode ser útil para a realização da sua aula. A colaboradora tem conhecimento do formato físico dos rods e quais possíveis usos podem ser efetivados, com este conhecimento e sua experiência de ter observado outras professoras fazendo uso deles, planejou sua tarefa e explicou a sua sósia como faria uso desse material para abordar o conteúdo gramatical simple past.

(02) Carla

ENTÃO, os rods são estruturas pequenas de made::ira de/de diversos tama::nhos, e podem ser usados pra explicar:: geralmente são usados pra explicar:: eh: regras de/de/ de sintaxe, de/de gramá::tica né, formação de fra::sés/.../ai daí você va::i separan:::do né, os rods, você /você escolhe, fica a seu critério, você pega uma pecinha menor pra ser o prono::me, aí você entrega a todos, olhem, essa pecinha vai ser o prono::me, /.../ ai você pega outra pecinha pra ser o ver::bo, um pouquinho maior para eles diferencia::rem, [[né::/.../ ai daí:: tu/a ideia é pegar uma outra peça...pra que se/pra ser colocada junta daquela peça do verbo pra mostrar que fez o passa::do né:: regular com 'ed' /.../ ai daí, você pega uma outra peça porque ele vai aumentando de tamanho, você pega uma peça maior:: e faz como complemento da fra::se

No segmento (02), a professora Carla é bem minuciosa quando explica a sua sósia como deveria usar os rods nas falas: "você pega uma pecinha menor pra ser o pronome", "você pega outra pecinha pra ser o verbo, um pouquinho maior" e "você pega uma peça maior e faz como complemento da frase", ela está explicando à pessoa que a substituirá na sua aula como deve usar esse material. No entanto, na prática ela ainda não sabe se funcionará, pois anteriormente ela menciona que nunca fez uso dessa ferramenta. Ainda afirma que "geralmente são usados para explicar regras" o que nos indicia certo conhecimento do seu uso dos rods em conteúdos específicos.

Em outro momento, Carla evidencia na sua fala a preocupação em mediar o conhecimento dos discentes. Isto leva a colaboradora a (re)configurar seu agir, o que pode ser conferido no segmento (03):

(03) Carla

é bom que sejam rods diferen::tes porque tate/tate/tateando eles vão ver né:: que porque a ideia dos rods:: é que mentalmente eles for::memeh:: eles internalizem, eles formem na cabeça de::les, da forma que a gente faz usualmente a gente vê o professor colocando no quadro a regra, a gente vê o que é a posição de cada um né::. 
Falamos em (re)configuração no sentido de um agir, adquirir novas formas, contornos, novos caminhos para um ensino que inclua a todos seus alunos sem exceção. No contexto imediato em que se encontra a professora Carla, que seria o ICP, na voz dessa colaboradora, observamos que ela busca sistematizar o uso dos rods de forma a propiciar um meio onde os alunos aprendam o conteúdo escolhido e desenvolvam determinadas capacidades (MACHADO \& BRONCKART, 2009). Quando a professora afirma "é bom que os rods sejam diferentes" e "a ideia dos rods é que mentalmente eles formem, eles internalizem /.../ formem na cabeça deles, da forma que a gente faz usualmente" ela está preparando esse meio para que a aprendizagem se torne possível.

Assim, Carla revela um julgamento subjetivo em relação à utilidade dessa ferramenta, para ela se torna um requisito que os rods sejam de tamanhos diferentes para poder cumprir seu objetivo que é que os alunos mentalmente formem e internalizem o que está sendo ensinado. Ainda destaca que a forma de aprender internalizando e formando frases mentalmente é uma maneira usual das pessoas que enxergam construírem conhecimento. Ao realizar a comparação, "a gente vê o professor colocando no quadro a regra" e "a gente vê o que é a posição de cada um né" observamos que a ação do professor de colocar no quadro é (re)configurada através dos rods, pela troca de ferramentas materiais usadas em sala de aula, mas que cumpririam o mesmo objetivo.

Também observamos que o agir da professora Carla ao ser (re)configurado cria um meio propício para a aprendizagem dos seus alunos com NEV, mesmo não sabendo se terá o resultado que espera, já que ainda está se apropriando dessa ferramenta. Esta tentativa de apropriação é válida, pois é dessa forma que ela dará novos significados ao seu agir. Carla sabe disso, pois ela mesma reflete que "isso acontece né em qualquer sala de aula, a gente vai adaptando, a gente planeja” (Extraído da entrevista Instrução ao Sósia).

Outro aspecto que saltou aos olhos foi a fala da professora de ter que improvisar na sala de aula, devido a uma situação inusitada. Machado (2007) já mencionava que o trabalho do professor se vê em situações tão específicas nas quais precisa (re)configurar seu agir mas não somente diante de situações diversas, mas de vozes contraditórias, do agir dos outros, do meio, dos artefatos e das prescrições. Assim, vejamos no segmento (04) como Carla age quando descobre que o seu aluno com baixa visão, que até então lia textos na fonte aumentada, não enxerga mais.

\section{(04) Carla}

Então cheguei pra aula com o material preparado, escrito só que na fonte aumentada, e daí quando eu vou ver ele não enxerga mais, então na hora improvisei com tampa de caneta, borra:: :cha, improvisei a formação de frases assim

No excerto acima, vemos como o agir da professora Carla teve que ser (re)configurado para poder dar seguimento a sua aula e tornar possível a aprendizagem do seu aluno com NEV. A voz da professora evidencia claramente esta (re)configuração quando menciona "cheguei pra aula com o material preparado, escrito só que na fonte aumentada" e "na hora improvisei com tampa de caneta, borracha". As ferramentas, tampa de caneta e borracha, que até então não tinham utilidade para a professora, tornaram-se instrumentos para mediar a aprendizagem do discente. Foi usando-as como partes de uma frase que a professora conseguiu dar seguimento a sua aula e principalmente possibilitou que o seu aluno não ficasse fora do processo de ensino-aprendizagem.

Observamos até aqui a predominância de ferramentas que ajudam na visualização mental, seja de estruturas, formas, tamanho, entre outros. No ensino a alunos com NEV, tornam-se indispensáveis este tipo de ferramentas para criar um meio que medeie a aprendizagem de conteúdos específicos e consequentemente que o aluno se desenvolva como qualquer outro. 
Até aqui temos analisado as ferramentas materiais evidenciadas nos textos da colaboradora desta pesquisa. A seguir, refletimos sobre a ferramenta simbólica metodologia de leitura em sala de aula com alunos com deficiência visual e de como ela deve ser realizada.

\section{(5) Carla}

daí eu entro o material em Braille que tem as re::gras, e daí nós vamos ler juntos /.../[[sim a leitura, o que eu aprendi é que eles têm que ler, porque a leitura em Braille, É lenta, e daí já é lenta assim, eles/é uma leitura que naturalmente é mais devagar porque não é/.../ uma leitura com o dedo, entã::o eles vão identificando palavra por pa:la::vra, então é uma leitura mais lenta.

$\mathrm{Na}$ fala de Carla entendemos que faz uma reflexão da leitura em Braille realizada pelos alunos com NEV, contrastando-a com a de um vidente no sentido de ela ser mais lenta, já que essa ação é efetuada pelos alunos sistematicamente, palavra por palavra. Observamos no dizer da docente que o contexto imediato em que se encontra propiciou que ela adquirisse conhecimento em relação à leitura em Braille. Provavelmente, fora desse contexto, ela não teria essa informação devido à falta de disciplinas nas graduações que abordem esse tema. Destacamos aqui a importância de o professor estagiar em contextos diferentes de ensino, pois é através do contato com o outro que nossas representações sobre o ensino de língua estrangeira ganharão novos significados.

Por outro lado, percebemos que a representação que Carla tem em relação à metodologia de leitura em sala de aula é (re)configurada, ela se apropria de uma nova forma de realizá-la com seus alunos. Quando afirma, "eu aprendi é que eles têm que ler porque a leitura em Braille é lenta" destacamos o verbo têm, e podemos associá-lo a uma prescrição. Muito provavelmente a colaboradora adquiriu este novo agir observando as professoras que já vem dando aula no ICP, e esta forma de leitura também se tornou uma prescrição para elas na sua prática docente.

No segmento (06), Carla relata como foi sua experiência com a leitura em Braille e justifica, mais uma vez, a necessidade dos discentes realizarem a leitura, vejamos:

\section{(6) Carla}

eu percebi que quando a gente lê:: né porque eu tenho a minha cópia, quando eu le:::io, eu não sei em que ritmo cada um tá acompanhando, então eles podem estar muito atrás do que tô lendo ou mais na frente, então você pede pra cada um ler um pouquinho, ai vai pausan::do, vai explican::do.

A incerteza de Carla de não saber se, no processo de leitura, os alunos com NEV estão acompanhando seu ritmo de leitura é evidente. Contudo, resolve esse impasse refletindo mais uma vez que a leitura deve ser realizada pelos alunos, e a verificação do seu entendimento pela professora deve efetuar-se pausando e explicando. Na fala de Carla "você pede para cada um ler um pouquinho" destacamos o uso do verbo pedir, que indica uma obrigatoriedade de os alunos lerem, uma ação necessária.

Nesse processo de leitura, onde os discentes leem em Braille, vemos a importância, mais uma vez, da formação inicial no sentido de prover o professor em formação deste conhecimento. Na falta dela, nossa colaboradora tenta (re)configurar seu agir com o intuito de não comprometer a construção de conhecimentos dos alunos.

\subsection{As prescrições}

Segundo Amigues (2004), as prescrições cumprem a função de desencadeadoras da ação do professor, também constituem sua atividade ao serem redefinidas por ele, já que elas são vagas. Por outro lado, são definidas também como as limitações/ 
coerções/regras/normas explicitamente tematizadas em textos, que são direcionadas aos trabalhadores e produzidas por uma instância hierarquicamente superior (BERTHET E CRU, 2002 apud BUENO, 2007). Nos dizeres da colaboradora Carla, as prescrições que foram identificadas giram em torno do tema da organização da sala e do narrar cada ação que a professora realiza em sala de aula. Vejamos no segmento (7) como a docente prescreve a sua sósia o que tem que fazer assim que entrar na sala de aula:

\section{(7) Carla}

entra na:: sa::la, /.../ as cadeiras estão dispostas assim, em file::iras horizonta::is, então assim, NÃO é bom:: mexer nas cad/na organização das cadeiras porque eles já sabem que a organização É essa /.../ai é importante /.../ porque eles/eles né eles guar::dam a localização né, mentalmente né::/.../ eu digo SE for mudar:: você avisa, porque tudo que a gente vai fazer, que eu apren::di, com deficientes visuais, a gente tem que NArrar o que a gente vai fazer

Uma das primeiras ações a ser realizada pela professora é organizar a sala de forma que os alunos não sintam dificuldade em se locomover. Isto pode ser verificado quando Carla faz a orientação a sua sósia "não é bom mexer na organização das cadeiras". Nesta fala, Carla faz um julgamento subjetivo em relação a alterar a ordem das cadeiras, onde o ideal é mantê-las na mesma posição. Ainda avalia esta prescrição como importante, pois os alunos já conhecem a posição de cada uma. No dizer da colaboradora podemos observar que ela vai das ações individuais às coletivas, o uso do pronome a gente identifica um coletivo, ela e as outras professoras do ICP ou ela e a outra professora bolsista do PROLICEN.

Ainda, é interessante destacar que a prescrição é evidenciada na fala de Carla quando ela afirma "a gente tem que narrar", verbo ter implica uma obrigação, uma ação necessária. Assim, verificamos que, nas ações de Carla, houve uma (re)configuração do seu agir frente ao novo contexto em que se encontra inserida. A prescrição de não mexer na organização da sala e narrar tudo que a professora vai fazer são novas representações do trabalho docente que estão sendo adquiridas como fruto de reflexões e do coletivo próximo.

\subsection{Regras do oficio}

Segundo Bueno (2007) as regras do ofício se constroem no decorrer da história e se referem aquilo que liga os profissionais entre si, isto é, uma memória comum, uma caixa de ferramentas, onde as regras podem reunir gestos relativos. Nesta categoria de análise, três foram os temas evidenciados na voz da participante desta pesquisa: a correção da pronúncia, a tradução e criar aula de língua estrangeira para alunos com NEV. A colaboradora Carla aborda o primeiro tema quando explica os procedimentos de leitura de um texto, vejamos:

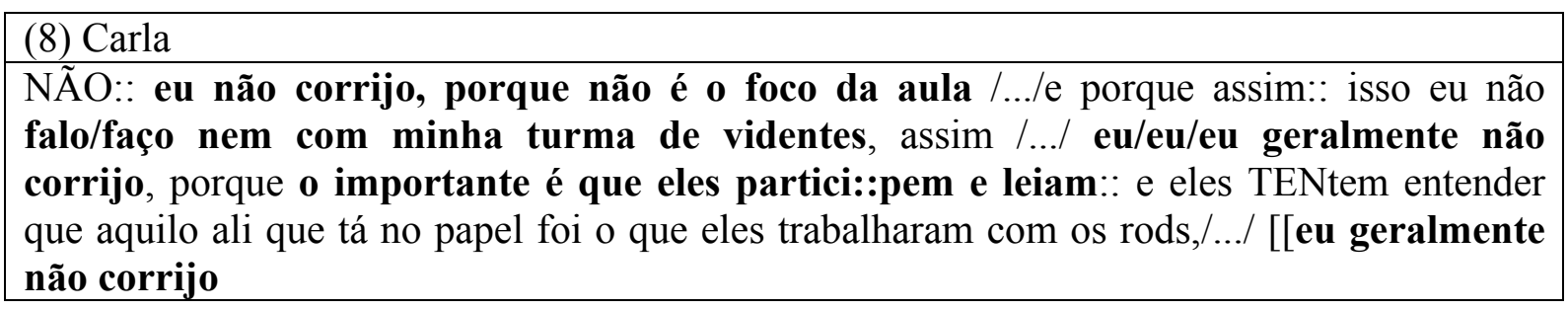

Observamos, no fragmento acima, que a professora tem uma representação formada em relação a quando corrigir a pronúncia, sua experiência de ensino lhe permitiu adquirir certo conhecimento sobre sua profissão, o que de uma forma geral, the orienta a realizar ações específicas dependendo da situação/contexto. Assim, em relação à correção da pronúncia em exercícios de leitura com seus alunos com NEV, Carla afirma "eu não corrijo, porque não é o foco da aula", e ainda enfatiza "eu não falo/faço isso nem com a minha turma de videntes". A 
justificativa para esta ação é achar importante que seus alunos participem da leitura, isto é, ela tem bem claro que quando o exercício é de leitura não corrige a pronúncia, porque o foco/objetivo não é esse.

O segundo tema abordado pela colaboradora foi a tradução, a memória comum dos professores de língua estrangeira diz como deve ser. A seguir, Carla evidencia nos textos suas representações em relação à tradução:

(9) Carla

sim, pode traduzir, na verda::de, a aula de lá::: as aulas lá não são aulas assim::: pelo menos nesse contexto, não/não é proibida a tradução, na verdade é até:: um tipo de aula instrumental, de ensino de lín::guas::/.../ não é um curso de idiomas né::/../ é um curso PAra trazer conhecimen::to, da língua inglesa, então:: não tem problema traduzir não

A experiência no ensino, mais uma vez, influência as ações da professora Carla, no tema tradução, ela afirma "sim, pode traduzir" que "não é proibida a tradução", mas será seu contexto imediato que a fará refletir e decidir se a tradução é permitida. No caso específico do ICP, ela afirma que as aulas são do tipo instrumental, "não é um curso de idiomas", mas que são trabalhadas as quatro habilidades. A fala da professora evidencia que ela já trabalhou em vários lugares, não somente no ICP ou cursos livres de idiomas e isto the proporciona o conhecimento de saber como deve ser abordada a tradução.

Continuando no mesmo tema, no segmento (10), ela especifica como deve ser realizada esta tradução, vejamos:

(10) Carla

se eles não souberem, é bom perguntar, entenderam::: tem alguma palavra que vocês não conhe::cem? E daí né, se alguém falar, não essa palavra professora, você joga pra eles de novo, alguém sa::be que palavra é essa? Vocês já viram em algum texto, já estudaram?

No trecho em questão, Carla não faz a tradução diretamente, ela parte do conhecimento prévio do aluno perguntando "entenderam, tem alguma palavra que vocês não conhecem", "alguém sabe que palavra é essa?", "vocês já viram em algum texto, já estudaram?" Partir do conhecimento prévio do aluno é uma estratégia usada por várias abordagens de ensino, por exemplo, a abordagem comunicativa, muito conhecida no contexto de ensino-aprendizagem de línguas estrangeiras em escolas livres de idiomas, e tornou-se uma memória comum a todos os professores de LE. Para acessar a esse conhecimento, Carla prescreve a sua sósia que "é bom perguntar". Neste tema em questão, no ensino a alunos com $\mathrm{NEV}$, não houve uma (re)configuração no agir de Carla, ela usou os conhecimentos adquiridos, da forma como os concebera e os aplicou também neste novo contexto.

O terceiro tema abordado pelas colaboradoras dentro da categoria regras do ofício foi o de criar aula de língua estrangeira para alunos com NEV. A continuação, temos a voz de Carla no segmento (11):

\section{(11) Carla}

é um mundo novo né:: a gente não tem essa preparação:: essa formação na universidade, então você vai tentan::do, você vai len::do, tendo contato com as professo::ras que já trabalham com isso e você vai tentando né:: vai fazen::do e tentan::do que na verdade é uma aula normal::como qualquer outra aula SÓ que precisa fazer as adaptações.

No excerto acima, refletimos que a colaboradora encontra-se em um contexto novo de ensino, situação nova que pede dela uma (re)construção do seu gênero profissional para poder criar um meio de aprendizagem e desenvolvimento dos seus alunos com deficiência visual. $\mathrm{Na}$ voz de Carla é evidenciada a representação que ela tem de como é criar aula para esse 
grupo de alunos. A colaboradora menciona que é um mundo novo e que, na formação inicial, "não tem essa preparação", mas que está começando por meio de tentativas, leituras, no contato com professoras que já trabalham nesse âmbito. É a traves dessas ações que a colaboradora vai (re)configurando seu agir, porque afinal, como ela menciona, a aula para alunos com NEV "é uma aula normal como qualquer outra só que precisa fazer adaptações".

\subsection{Os coletivos}

Segundo Bueno, os coletivos podem ser "tanto um grupo de pessoas como também uma memória coletiva que cada professor carrega em si, retomando-a a cada momento de seu trabalho para validar um artefato, questionar uma regra, criticar um comportamento, etc" (BUENO, 2007, p. 50). Com base nesta definição e da importância do coletivo no agir dos professores, a docente Carla que ensina no ICP evidenciou nos seus textos como este elemento constituinte do trabalho do professor faz toda a diferença para que haja uma (re)configuração do seu agir. No processo de apropriação de uma ferramenta, no segmento (12), a professora Carla faz referência no seu discurso a professoras do seu entorno imediato de trabalho, especificamente, professoras que já ensinam faz algum tempo no ICP, vejamos:

\section{(12) Carla}

então daí:: na verdade estou dizendo isso mas eu nunca dei aula disso, vai ser a primeira vez que vou trabalhar os rods, eu SÓ vi as professoras dando aula com os rods, mas eu nunca usei.

No segmento acima, Carla se encontra em processo de apropriação da ferramenta rods, ela afirma claramente, "vai ser a primeira que vez eu vou trabalhar os rods", "nunca usei". Baseados no pressuposto de que no coletivo ocorre uma troca de saberes, enfatizamos a importância das professoras mencionadas no dizer da docente. Estas professoras, Beatriz e Renata, já se apropriaram dos rods e enquanto agem, servem de exemplo para que Carla se interesse por essa nova ferramenta e crie um objetivo para ela. A colaboradora corrobora o papel que as professoras cumprem na sua formação quando ela afirma "eu só vi as professoras dando aula com os rods".

No quesito leitura já abordado nesta seção, falamos que a leitura em Braille era lenta e que era recomendável que fosse realizada pelos próprios alunos, visto que, dessa forma, o professor acompanharia melhor o ritmo de leitura dos alunos. Neste cenário, no segmento (13) a professora Carla chama a atenção para a informação que Renata, professora do ICP, fornece para ela sobre a leitura deste código:

\begin{tabular}{l}
\hline (13) Carla \\
E::: também assim:: segundo Renata:: alguns alunos ali não tem facilidade em leitura \\
mes::mo, assim de Braille, leitura de língua mãe, /.../ então é uma coisa que tem que ser \\
bem::: deva::gar, porque eles tem essa dificuldade com a leitura, que/que foi o que Renata \\
me passou
\end{tabular}

A informação dada pela professora Renata sobre os alunos com NEV e a leitura em Braille é indispensável para Carla faça uma (re)configuração do seu agir em relação a leitura. Renata relatou que "alguns alunos ali não tem facilidade em leitura mesmo" e que "a leitura tem que ser bem devagar" devido à dificuldade. Assim, uma leitura que poderia ser realizada pela docente e ainda num ritmo mais acelerado, como acontece nas turmas onde só tem videntes, se (re)configura em virtude da informação compartilhada sobre os alunos. No contexto do ICP, o coletivo próximo torna-se essencial para que a colaboradora (des)construa seu gênero profissional. Sem este coletivo, acreditamos que Carla se sentiria aflita frente ao novo contexto e provavelmente suas aulas não seriam tão inclusivas como deveriam ser. 


\section{Algumas considerações finais}

Considerando o objetivo da nossa pesquisa - investigar como os elementos constitutivos do trabalho docente de uma professora de língua inglesa a alunos com necessidades específicas visuais indiciam (re)configurações do seu agir linguageiro, recorrendo aos pressupostos teórico metodológicos do ISD e dos aportes teóricos das Ciências do Trabalho no que se refere aos objetos constitutivos do trabalho docente e seus conceitos sobre trabalho - identificamos que as ferramentas e as regras do ofício foram mencionadas consideravelmente nos dizeres da colaboradora.

$\mathrm{Na}$ categoria ferramentas, ambos os tipos, materiais e simbólicas foram mencionadas, entre as materiais se destacaram os rods, material escrito em Braille e tampa de caneta e borracha; nas simbólicas tivemos a metodologia de leitura. As regras do ofício mencionadas foram a correção da pronúncia, a tradução e criar aula de língua estrangeira para alunos com NEV. Em relação a este elemento constitutivo ser considerado como "uma caixa de ferramentas" (AMIGUES, 2004), observamos que em alguns casos, a colaboradora já têm suas representações formadas como, por exemplo, na correção da pronúncia e da tradução, de quando devem ser realizada e como. Assim, também, a representação sobre como é dar aula em escola regular e como criar aula de língua estrangeira para vidente é clara. No entanto, quando se trata das aulas a alunos com NEV, esta memória comum ainda está em construção, fazendo com que os professores entrem em conflito ou se sintam despreparados para lidar com alunos com deficiência visual.

Em relação às prescrições, identificamos a necessidade de manter a organização da sala de aula, do jeito que os alunos a conhecem e o narrar de cada ação que a professora realiza, pois na reflexão da colaboradora, sem essa prescrição os alunos do ICP se sentiriam perdidos. Os coletivos também estiveram presentes, no contexto onde a nossa colaboradora atua, o ICP, é interessante destacar o papel que cumprem as professoras Beatriz e Renata, que já vêm atuando no ensino a alunos com NEV. Nesse coletivo imediato, no contato com essas professoras mais experientes, ocorre uma troca de saberes, essencial para Carla.

Verificamos também que, no processo de apropriação das ferramentas, há uma (re)configuração do agir da docente com o intuito de que os alunos com NEV possam participar ativamente das aulas e desta forma construir conhecimento. Outras ações que nos indicam que houve (re)configuração do agir foi o narrar das ações da professora considerada como essencial por Carla e a organização da sala. Estas (re)configurações, a princípio, nos indiciam ações/tentativas de que estes alunos se sintam incluídos em sala de aula, isto é, que dentro de suas capacidades possam participar ativamente do processo de ensino-aprendizagem com autonomia. Outras ações que revelam mais (re)configurações foi a presença de outras professoras mais experientes, isto no contexto do ICP. Este coletivo medeia a apropriação de novos instrumentos e de novas ações, permite que a colaboradora em formação façam uma reflexão entorno do seu agir, (des)construindo representações e consequentemente (re)configurando seu agir com o objetivo de torná-lo mais inclusivo.

Destacamos a necessidade de uma formação inicial baseada no paradigma da inclusão, e principalmente, que sejam implantados nos cursos de licenciatura estágios em instituições como o Instituto dos Cegos, para que os alunos vivenciem realidades diversas e desta forma reflitam sobre seu agir e consequente entendam a necessidade de (re)configurá-lo em prol de um ensino cada vez mais inclusivo. Enfatizamos que a escolha do instrumento de geração de dados, a Instrução ao Sósia, cumpriu o objetivo de o professor se autoconfrontar com sua atividade ao longo da entrevista. Isto é, buscávamos que a colaboradora dialogasse consigo mesma no sentido de olhar para sua própria experiência com olhos crítico-reflexivos.

\section{Referências}

AMIGUES, René. Trabalho do professor e trabalho de ensino. In: MACHADO, Ana Rachel. (Org.). O ensino como trabalho. São Paulo: EDUEL, 2004. p. 37-53. 
BRASIL. Política Nacional de Educação Especial na Perspectiva da Educação Inclusiva. São Paulo: MEC/SEESP, 2007. Disponível em: <http://peei.mec.gov.br/arquivos/ politica_nacional_educacao_especial.pdf $>$. Acesso em: 05 abr. de 2018. BRONCKART, Jean-Paul. Atividade de linguagem, discurso e desenvolvimento humano. $2^{\text {a }}$ Edição. São Paulo: Mercado de Letras, 2006.

O Agir nos discursos: das concepções teóricas às concepções dos trabalhadores. $1^{\text {a }}$ Edição. São Paulo: Mercado de Letras, 2008.

BUENO, Luzia. A construção de representações sobre o trabalho docente: o papel do estágio. 205f. 2007. Tese (Doutorado em Linguística Aplicada e Estudos da Linguagem). Pontifícia Universidade Católica, São Paulo, 2007.

CELANI, Maria Antonieta A. Questões de ética na pesquisa em Linguística Aplicada. In: Linguagem \& Ensino, vol. 8, nº 1, p. 101-122, 2005. Disponível em:

$<$ http://www.rle.ucpel.tche.br/index.php/rle/article/view/198/165>. Acesso em: 19 mar. 2018. CLOT, Yves. A função psicológica do trabalho. $2^{\text {a }}$ Edição. Petropolis, RJ: Vozes, 2007. COSTA, Vanderlei Balbino Da. Inclusão escolar do deficiente visual no ensino regular. $1^{\mathrm{a}}$ Edição. Jundiaí: Paco Editorial, 2012.

DENZIN, Norman K.; LINCOLN, Yvonna S. O planejamento da pesquisa qualitativa: teorias e abordagens. $2^{\text {a }}$ Edição. Porto Alegre: Artmed, 2006.

GUIMARÃES, Ana Maria de Mattos. O agir educacional nas representações de professores de língua materna. In: GUIMARÃES, Ana Maria de Mattos et al. O Interacionismo Sociodiscursivo: questões epistemológicas e metodológicas. São Paulo: Mercado de Letras, 2007. p.201-219. MACHADO, Anna Rachel. Por uma concepção ampliada do trabalho do professor. In: GUIMARÃES, Ana Maria de Matos et al. O Interacionismo Sociodiscursivo: questões epistemológicas e metodológicas. São Paulo: Mercado de Letras, 2007.p.77-97.

MACHADO, Anna Rachel; BRONCKART, Jean-Paul. (Re) configurações do trabalho do professor construídas nos e pelos textos: a perspectiva metodológica do grupo ALTER-LAEL. In: MACHADO, Anna Rachel; ABREU-TARDELLI, Lílian Santos; CRISTÓVÃO, Vera Lúcia Lopes (orgs.). Linguagem e educação: o trabalho do professor em uma nova perspectiva. São Paulo: Mercado de Letras, 2009, p.31-77.

MANTOAN, Maria Teresa Eglér. Inclusão escolar - O que é? Por quê? Como fazer?. $1^{\mathrm{a}}$ Edição. São Paulo: Summus, 2015.

MOITA-LOPES, Luiz Paulo da. Por uma linguística aplicada indisciplinar. $1^{\text {a }}$ Edição. São Paulo: Parábola, 2006.

. Pesquisa Interpretativista em Linguística Aplicada: a linguagem como condição e solução. In: DELTA, Vol 10, n²2, 1994, p. 329-338.

SIGNORINI, I.; CAVALCÂNTI, M. C. (orgs.). Linguística Aplicada e transdisciplinaridade. $1^{\text {a }}$ Edição. Campinas: Mercado de Letras, 1998. TOGNATO, Maria Isabel Rodrigues. A (re)construção do trabalho do professor de inglês pela linguagem. 335f. 2009. Tese. (Doutorado em Linguística Aplicada e Estudos da Linguagem). Pontifícia Universidade Católica de São Paulo, São Paulo, 2009. Disponível em: $<$ http://www.sapientia.pucsp.br/tde_busca/arquivo.php? codArquivo=9263 $>$. Acesso em: 23 mar. 2018.

SAUJAT, F. Ergonomie de l'activité enseignante et développement de l'expérience professionelle: une approche clinique du travail de professeur. 2004. Tese (Doutorado em Ciências da Educação). Université d'Aix-Marseille I, 2002.

Submetido em 26/09/18

Aceito em 10/12/2018 